SANG HYUK LEE, Ph.D.

E-mail: sanghyuklee8612@gmail.com

DAESEOK HAN, Ph.D.

E-mail: handaeseok@kict.re.kr

Korea Institute of Civil Engineering and Building Technology

283, Goyangdae-Ro, Ilsanseo-Gu, Goyang-Si,

Gyeonggi-Do, 411-712, Republic of Korea
Safety and Security in Traffic

Preliminary Communication

Submitted: Oct. 14, 2014

Approved: Feb. 2, 2016

\title{
SAFETY IMPACTS OF THE ACTUATED SIGNAL CONTROL AT URBAN INTERSECTIONS
}

\begin{abstract}
To reduce travel time, the actuated signal controls have been implemented at urban intersections. However, the safety impacts of actuated signal controls thus far have rarely been examined. In this assessment of the safety impact of urban intersections with semi-actuated signal controls, the safety performance functions and EB approaches were applied. The semi-actuated signal controls have increased injuries and total crashes in all crash types by around 5.9\% and $3.8 \%$, respectively. Regarding the most common crash types, such as angle, sideswipe \& rear-end, and head-on crashes, semi-actuated signal controls have been seen to decrease injuries by $7.7 \%$. Total crashes have been reduced by over 9.2\% through the use of semi-actuated signal controls. This may be result of optimal signal timings considering traffic conditions during peak time periods. In conclusion, safety impact factors which have been established in this study can be used to improve safety and minimize travel times using semi-actuated signal controls.
\end{abstract}

\section{KEY WORDS}

semi-actuated signal controls; safety impacts; safety performance functions; EB approaches; urban intersections;

\section{INTRODUCTION}

Since the 1970s, with an increase in traffic demands and the extended urban sprawl, the number of vehicle crashes has been rapidly rising in Korea. Each year, more than 220,000 crashes occur on public roads and over 340,000 people are injured. Additionally, more than 5,000 people lose their lives in road accidents. Due to the steady increase in traffic, a higher number of vehicle crashes occur in urban areas, particularly at urban intersections. In Korea, around 45\% of all vehicle crashes occur at urban intersections. Vehicle crashes associated with urban intersections cause $47 \%$ of injuries and $28 \%$ of deaths out of all vehicle accidents.
Over the last decades, the transportation engineers have been struggling to solve urban traffic problems, such as traffic congestion and poor traffic safety. However, these problems are often conflicting, as a faster flow of traffic means an increase in driving speed, which can lead to an increase in vehicle crashes [1]. For improved travel time and traffic safety, new technologies, such as red light camera and actuated signal control, have been implemented at urban intersections. Generally, the actuated signal controls are classified into two systems: the fully-actuated and semi-actuated signal control. The actuated signal control is recognized as the appropriate method for isolated intersections where traffic demands and patterns vary. The semi-actuated signal control is used mainly at isolated intersections located in major arterial and minor arterial crossings. In Daejeon metropolitan city, the fifth most populated city in Korea with approximately 1.5 million residents, the semi-actuated signal controls have been mainly implemented at urban intersections to improve the travel time. Daejeon was the first city designated for the pilot project involving the implementation of advanced transportation systems, such as ITS (Intelligent Transportation System) in 2000. Daejeon was used as a pilot project to gain accurate data for the analysis of safety impacts of semi-actuated signal controls.

Over the last decade, a number of studies conducted in many different cities and countries around the world have concentrated on assessing the safety impact of red light camera. However, the effectiveness analysis of actuated signal control at urban intersections has not been attempted. Many studies have been carried out to optimize signal timing or to study the effectiveness and efficiency of signal operation. However, these studies do not necessarily account for the safety impacts of the actuated signal control. This study focuses on the analysis of safety impacts 
of semi-actuated signal controls in Daejeon using EB (Empirical Bayesian) approaches.

With the current practice, various methods and models have been developed for the safety assessments of urban intersections. However, only a few studies have been conducted to analyze the safety impacts of urban intersections with actuated and semi-actuated signal controls. To overcome the limitations of obtaining information regarding the relationship between the implementation of actuated/semi-actuated signal controls and vehicle crash frequencies, useful methods and models should be benchmarked and applied to assess the safety impacts. This assessment uses various qualitative and quantitative methods. For instance, Young et al. (2009) introduced safety impacts for an incident reduction function into an actuated sig nal controller using a discrete event traffic micro-simulation model. The study results show that this technique can reduce vehicle crashes by $22 \%$ and red light violations by $6 \%$ [2]. Li et al. (2010) developed multinomial logit models to estimate the crash likelihood of safety impacts of signal coordination and other road and traffic variables. This study focused on particular crash types, such as rear-end and right-angle collisions, as well as crash severity affected by signal coordination [3]. Yun et al. (2011) conducted comparison analysis of the safety impact of fixed-time signal control, fully actuated signal control, and semi-actuated signal control using the Surrogate Safety Assessment Model based on the conflict theory developed by FHWA [4]. Kim et al. (2002) carried out the enhancement of actuated signal control safety to minimize the dilemma zone using Volume-Density control, R-detector, and ECDC Control. It has been concluded that the appropriate strategies result in minimized dilemma zones to improve intersection safety [5].

Regarding modelling safety performance functions, many statistical methods have been used, depending on the factors such as traffic volume and geometric information as well as other characteristics of urban intersections. Lord et al. (2000) developed an accident prediction model (APM) with an application of generalized estimating equations (GEE) that incorporates trends in accident data. The accident prediction model reflects the variation in accident occurrences from year to year [6]. Ma et al. (2006) developed models of injury count by severity using a type of multivariate Poisson specification which can be estimated in a Bayesian framework using Gibbs Sampling [7]. Persaud et al. (2002) demonstrated the complexity of calibrating macroscopic accident prediction models for urban intersections. These models were used in the Empirical Bayesian methods which can examine the actual accident experience of a specific intersection and compare it to the expected safety performance of similar intersections (compared groups) [8]. Heydeck- er et al. (2001) and Miaou et al. (2003) analyzed traffic safety on roads and intersections using Empirical Bayesian methods with crash frequency data $[9,10]$. Additionally, Miaou et al. (2003) compared the Empirical Bayesian methods and Full-Bayesian methods for modelling traffic crash-flow relationship for intersections [10].

\section{METHODOLOGY}

\subsection{Steps of proposed study methodology}

The proposed methodology for the analysis of safety impacts at urban intersections with semi-actuated signal controls in Daejeon comprises three steps: i) Data processing from scattering sources to estimate the safety impacts of intersections with semi-actuated signal control using geometric information and crash data of relevant intersections, ii) Development of SPFs (Safety Performance Functions) using data from intersections without fully and semi-actuated signal controls implemented, and iii) EB analysis of the effectiveness of urban intersections with and without semi-actuated signal controls before and after the implementation of semi-actuated signal controls at intersections.

The EB approach for analysing the safety impacts of urban intersections with semi-actuated signal controls is carried out in two steps: i) Estimating EB adjusted crash frequencies for semi-actuated signal control implementation before and after the implementation periods, and ii) Quantifying the safety impacts of semi-actuated signal controls by crash severity (injury and fatality).

\subsection{Development of safety performance functions}

\subsubsection{Consideration of SPF models}

SPFs are defined as statistical models for the prediction and explanation of vehicle crashes that use variables related to vehicle crash frequency. SPFs can be developed in comparison groups using geometric, vehicle crash, and traffic volume data from urban intersections without semi-actuated signal control, and they can be used for EB analysis. SPF models are also determined by the characteristics of dependent and independent variables, which may affect vehicle crash frequency. Previous studies regarding vehicle crash modelling have suggested that Poisson and negative binomial models have been used for modelling with discrete variables, such as vehicle crashes [11, 12, $13,14,15]$. Linear models of vehicle crashes may not show statistical significance, due to vehicle crash data, which is non-negative and discrete in nature. With linear models, the statistical assumption that the 


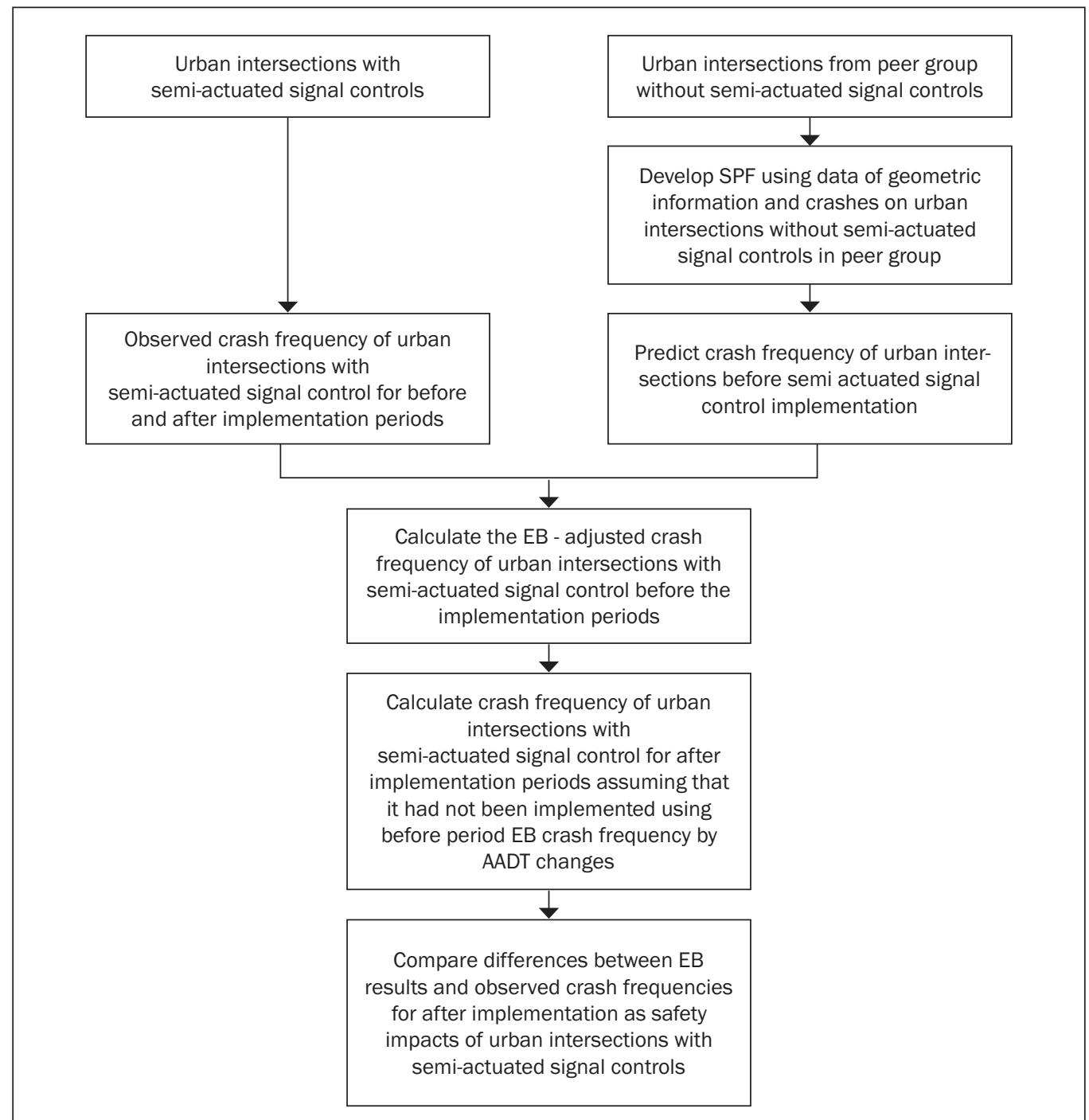

Figure 1 - Proposed methodology

error terms (residual) of vehicle crash data are typically normally distributed, is not satisfied [16].

The Poisson model assumes that crashes occurring at a particular urban intersection are independent of one another and independent of the mean number of crashes per unit time in the characteristics of a given intersection and of other intersections with similar properties. The general equation of the Poisson probability function and the mean are given by:

$$
\begin{aligned}
& P\left(Y=y_{i}\right)=\frac{\mu_{i}^{y_{i}} e^{-\mu_{i}}}{y_{i} !} \\
& \mu_{i}=\exp \left(\beta_{0}+\sum_{j=1}^{n} \beta_{j} x_{i j}\right)
\end{aligned}
$$

where $\beta$ is the vector of coefficients $\left(\beta_{0}, \beta_{1}, \ldots, \beta_{n}\right) ; y_{i}$ is the observed vehicle crash count at intersection $\mathrm{i}$; and $\mu \mathrm{i}$ is the expected number of crashes at intersection $\mathrm{i}$.

The value of $\beta$ that maximizes the log likelihood function is the estimated coefficient vector $\beta$ and the estimated value of $\mu_{i}$ is the expected vehicle crash frequency.
However, the Poisson regression model has a very strict assumption that the variance of the dependent variable is constrained to be equal to the mean of the dependent variable. If the data are over-dispersed (i.e., if the variance is greater than the mean), then the coefficient vector $\beta$ will be biased. Even though the Poisson Regression model has this limitation, it is still the basic model to determine vehicle crash frequency and it has many applications $[17,18]$.

To overcome the limitations of the Poisson regression model with over-dispersed data, the negative binomial regression model can be used to develop vehicle crash frequency models. The negative binomial regression model is considered as a generalized form of the Poisson regression model, since it has the same mean structure as the Poisson regression model and has an extra parameter to model over-dispersion. The negative binomial model and the variance of the negative binomial model are formulated as follows: 


$$
\begin{aligned}
& P\left(Y=y_{i}\right)=\frac{\Gamma\left[\frac{1}{\alpha}+y_{i}\right]}{\Gamma\left[\frac{1}{\alpha}\right] \cdot y_{i} !} \cdot\left|\frac{1}{\left(1+\alpha \mu_{i}\right)}\right|^{\frac{1}{\alpha}} \cdot\left[1-\left.\frac{1}{1+\alpha \mu_{i}}\right|^{y_{i}}\right. \\
& \operatorname{Var}(y)=\mu_{i}\left(1+\alpha \mu_{i}\right)
\end{aligned}
$$

where $\alpha$ is the over-dispersion parameter estimated by the maximum likelihood technique and $\Gamma$ is the gamma function.

The negative binomial regression model is estimated using the standard maximum likelihood method by applying the likelihood function. The negative binomial regression model is presented as follows:

$$
\begin{aligned}
& \operatorname{LL}(\beta)=\sum_{i=1}^{n}\left\{\left[\sum_{j=0}^{y_{i}} \log (1+\alpha \cdot j)\right]-\log \left(1+\alpha \cdot y_{i}\right)+\right. \\
& +y_{i} \cdot \log \mu_{i}-\left(y_{i}+\alpha^{-1}\right) \log \left(1+\alpha \cdot \mu_{i}\right)-\log \left(y_{i} !\right\}
\end{aligned}
$$

where $\alpha$ is the over-dispersion parameter; $\beta$ is the vector of coefficients $\left(\beta_{0}, \beta_{1}, \ldots, \beta_{n}\right) ; y_{i}$ is the observed crash count at intersection $i$; and $\mu_{i}$ is the expected number of crashes at intersection $i$.

The selection of the Poisson regression model and the negative binomial regression for vehicle crash modelling depends on the statistical significance of the over-dispersion factor. If the over-dispersion factor is not significantly different from zero, the Poisson model is considered to be the correct choice. If the over-dispersion factor is greater than zero, then the negative binomial model is considered to be appropriate method for modelling the vehicle crash frequency.

\subsubsection{Considering zero inflation}

The crash data may have a large number of observations with zero crash occurrences. In fact, many intersections experience zero vehicle crashes in a given year. In these cases, the zero inflated Poisson model or the zero inflated negative binomial model can be used to develop the vehicle crash frequency model $[11,17]$. These zero inflated models estimate two crash models simultaneously, the count model and the zero count model. The basic zero inflated concept is shown as follows:

$Y \backsim\left\{\begin{array}{cc}0 & \text { with Probability } p_{i} \\ P\left(Y=y_{i}\right) & \text { with Probability } 1-p\end{array}\right.$

Additionally, the zero inflated Poisson model is given by:

$$
\begin{aligned}
& P(Y=0) p_{i}+\left(1-p_{i}\right) e^{-\mu i} \\
& P\left(Y=y_{i} \neq 0\right)=\left(1-p_{i}\right) \frac{\mu_{i}^{y_{i}} e^{-\mu_{i}}}{y_{i} !}
\end{aligned}
$$

while the zero inflated negative binomial model is given by:

$$
\begin{aligned}
& P(Y=0)=p_{i}+\left(1-p_{i}\right)\left\lceil\left.\frac{1}{\left(1+\alpha \mu_{i}\right)}\right|^{\frac{1}{\alpha}}\right. \\
& P\left(Y=y_{i} \neq 0\right)= \\
& =\left(1-p_{i}\right) \cdot \frac{\Gamma\left\lceil\frac{1}{\alpha}+y_{i}\right\rceil}{\Gamma\left\lceil\frac{1}{\alpha}\right\rceil \cdot y_{i} !} \cdot\left\lceil\frac{1}{\left(1+\alpha \mu_{i}\right)}\right]^{\frac{1}{\alpha}} \cdot\left[1-\frac{1}{1+\alpha \mu_{i}}\right]^{y_{i}}
\end{aligned}
$$

In this study, model forms both with or without zero crash inflation are investigated in the Poisson regression model and the negative binomial regression model. The collected geometric information, vehicle crashes, and traffic volume data of urban intersections without semi-actuated signal controls in comparison groups are reflected in these models.

\subsubsection{SPF model validation}

In previous studies, the modelling processes using the Poisson and the negative binomial model were accomplished using NLOGIT econometrics software [19]. The NLOGIT software yields estimates of the coefficients as well as the standard errors for each coefficient from which the $p$-values and $t$-statistics can be computed. The likelihood ratio test is a common test used to assess two competing models [17]. Additionally, $R_{p}$-square of the Poisson regression model and $R_{\alpha}$ square of the negative binomial regression model can be computed to fit each test in an accurate manner. In addition, in order to consider a more detailed model validation, Akaike Information Criterion (AIC), Bayesian Information Criterion (BIC), and Vuong Test can be checked.

\subsection{Safety impact analysis from EB approaches}

\subsubsection{Computation of EB adjusted crash frequencies for the period prior to the implementation}

To predict vehicle crash frequency at urban intersections with semi-actuated signal controls for the period prior to the implementation, the EB adjusted crash frequency, which resolves the regression to the mean problem for the period prior to the implementation, needs to be estimated to carry out the analysis [18, 20, 21, 22]. The typical EB adjusted crash frequency model for the period prior to the implementation is demonstrated as:

$E B_{B}=W \cdot P_{B}+(1-w) \cdot O_{B}$

where $E B_{B}$ is the EB adjusted crash frequency in $n$ years for the period prior to the implementation; $w$ is the computed weight factor; PB is the number of predicted crashes for the period prior to the implementation, as stated by the SPF model; and $O_{B}$ is the total number of observed crashes in $n$ years for the period prior to the implementation.

The weight factor $w$ for a targeted intersection can be established based on the over-dispersion parameter determined in the process of calibrating the SPF, as follows:

$w=\frac{1}{1+\left\lceil\alpha \cdot(N) \cdot \sum_{n=1}^{N} P_{n, B}\right\rceil}$ 
where $\alpha$ is the over-dispersion parameter for crash frequency per year; $P_{n, B}$ is the predicted crash frequency for the intersection in year $n$ for the period prior to the implementation; and $n=1,2, \ldots, N$.

\subsubsection{Computation of EB adjusted crash frequencies for the after the implementation period}

In the EB approach process, the EB adjusted crash frequency for the period prior to the implementation can be used to predict an EB adjusted crash frequency for the after the implementation period if semi-actuated signal controls in the targeted intersections are not implemented in the after the implementation period. The computation needs to consider mainly the changes in average annual daily traffic (AADT) at the intersection between before and after the implementation periods. The EB adjusted crash frequency model for the 'after implementation period' is defined as,

$$
E B_{A}=E B_{B} \cdot\left\lceil\frac{\sum_{m=1}^{M}\left(A A D T_{m, \text { major }}+\left(A A D T_{m, \text { minor }}\right)\right.}{\sum_{n=1}^{N}\left(A A D T_{n, \text { major }}+\left(A A D T_{n, \text { minor }}\right)\right.}\right\rceil
$$

where $E B_{B}$ is the EB adjusted crash frequency for the period prior to the implementation; $E B_{A}$ is the $E B$ adjusted crash frequency for the after implementation period if the implementation of semi-actuated signal controls has not been implemented; and $A A D T_{n \text {,majo }}$ and $A A D T_{n, \text { minor }}, A A D T_{\text {m,major }}, A A D T_{\text {m,minor }}$ are the annual average daily traffic at the intersection of major and minor legs for the before and after implementation periods, respectively.

\section{SAFETY IMPACTS OF SEMI-ACTUATED SIGNAL CONTROL}

\subsection{Data collection and processing}

The EB approach, which is the proposed methodology, was applied using the data on urban intersections with and without semi-actuated signal control in Daejeon collected from 2007 to 2012. This section discusses the calibration of SPF for injury crashes associated with urban intersections and EB analysis for safety impacts of semi-actuated signal controls.

To develop the SPF models, this study obtained the data from 37 urban intersections without semi-actuated signal control in Daejeon for the period 2007 2012 from available databases provided by Daejeon Metropolitan City, Daejeon Metropolitan Police Agency and the Road Traffic Authority. The data from intersections have been maintained for up to six years. The summary of urban intersections without semi-actuated signal controls used for SPF calibration is shown in Table 1.

To develop SPFs, first geometrics, vehicle crashes, and traffic volume data from urban intersections as comparison groups should be appropriately classified into the dependent (response) and independent (explanatory) variables. In this study, the number of vehicle crashes per intersection per year in terms of crash severities (injury and total) is the dependent variable for SPF modelling. Factors that may affect vehicle crash frequencies, such as AADTs (the number of vehicle entering intersections), land usage, speed limits, traffic islands, the number of lanes in each leg, median barriers, cross walks, left and right turn pockets, auxiliary lanes, and front traffic signals that have been implemented at the entrances of intersections due to the large intersection size, and the like, are independent variables.

\subsection{SPF calibration}

The calibrating of SPFs in this study follows typical steps comprised of variable choices, SPF model choice, and model validation. First, a preliminary data analysis was conducted to obtain the distribution of independent variables and to identify variables, which may affect the occurrence of vehicle crashes at urban intersections. Second, the SPF model was formulated by adding each independent variable in a stepwise manner to test the effects of variables in vehicle crashes. Subsequently, the SPF model validation tests were conducted. Finally, SPFs at urban intersections were calibrated for injury crashes (injury A and injury B) and total crashes (all injuries and fatalities).

As with calibrating SPFs for urban intersections without semi-actuated signal controls, the Zero Inflated Poisson Regression with normal heteroscedasticity was formulated as the most accurate model of SPFs for injury and total vehicle crashes. These calibrations indicated that many intersections showed no occurrence of vehicle crashes for the study period and no apparent over-dispersion. For SPFs for both injury crashes and total crashes, the major road AADT,

Table 1 - Total number and crashes at urban intersections without semi-actuated signal control

\begin{tabular}{||l|c|c|c|c|c|c||}
\hline \multicolumn{1}{|c|}{ Intersection } & 2007 & 2008 & 2009 & 2010 & 2011 & 2012 \\
\hline \hline Numbers & 37 & 33 & 29 & 28 & 28 & 28 \\
\hline Fatal Crashes & 6 & 2 & 3 & 3 & 5 & 4 \\
\hline Injury A (Serious Injury) & 102 & 92 & 98 & 69 & 82 & 79 \\
\hline Injury B (Slight Injury) & 157 & 143 & 125 & 149 & 159 & 194 \\
\hline Total & 265 & 237 & 226 & 221 & 246 & 277 \\
\hline
\end{tabular}


number of lanes, speed limits, left turn pockets and front traffic signals were found to be significant.

To validate the calibrated SPF models, McFadden Pseudo $\mathrm{R}_{\mathrm{p}}{ }^{2}$, which represents the fit of SPF models, was computed, with the value of 0.701 for injury crashes and 0.705 for total crashes. This means that the calibrated SPF models were statistically significant for vehicle crash frequencies at urban intersections without semi-actuated signal controls.

\subsection{Estimation of safety impacts of semi- actuated signal control}

Since 2004 only 38 semi-actuated signal controls have been implemented at urban intersections in Daejeon Metropolitan City. Some of the semi-actuated signal controls have been operating for over nine years while others were implemented only recently. Additionally, many urban intersections with semi-actuated signal controls have shown no vehicle crashes during the specified study periods. Therefore, the targeted intersections with semi actuated signal controls were classified according to the implementation date and the number of vehicle crashes. Consequently, we gathered the data from 10 urban intersections with semi-actuated signal controls in Daejeon covering a period of six consecutive years (2007 2012) for the analysis of the safety impact.

The safety impacts of semi-actuated signal control are evaluated for total vehicle crashes and prevalent vehicle crash types at intersections, such as angle,

Table 2 - Calibration of SPFs for urban intersections without semi-actuated signal control

\begin{tabular}{|c|c|c|c|c|}
\hline & Models & Coefficients & Standard Error & P-Value \\
\hline \multirow{11}{*}{ Injury Crashes } & Constant & -6.087 & 1.162 & 0.000 \\
\hline & Ln(Major Road AADT) & 0.662 & 0.122 & 0.000 \\
\hline & Number of Lanes & 0.127 & 0.048 & 0.009 \\
\hline & Speed Limits & 0.009 & 0.003 & 0.001 \\
\hline & Left Turn Pockets & -0.929 & 0.132 & 0.000 \\
\hline & Front Traffic Signal & -0.550 & 0.116 & 0.000 \\
\hline & Dispersion & 0.503 & 0.068 & 0.000 \\
\hline & \multicolumn{4}{|c|}{ Log Likelihood Function = -783.972 } \\
\hline & \multicolumn{4}{|l|}{$\mathrm{AIC}=4.714 \mathrm{BIC}=4.805$} \\
\hline & \multicolumn{4}{|c|}{ McFadden Pseudo $\mathrm{R}_{\mathrm{p}}{ }^{2}=0.701$} \\
\hline & \multicolumn{4}{|c|}{ Vuong Test $=6.149$} \\
\hline \multirow{12}{*}{ Total Crashes } & Constant & -6.163 & 1.157 & 0.000 \\
\hline & Ln(Major Road AADT) & 0.674 & 0.122 & 0.000 \\
\hline & Number of Lanes & 0.121 & 0.049 & 0.013 \\
\hline & Speed Limits & 0.009 & 0.003 & 0.001 \\
\hline & Left Turn Pockets & -0.936 & 0.131 & 0.000 \\
\hline & Front Traffic Signal & -540 & 0.116 & 0.000 \\
\hline & Dispersion & 0.503 & 0.067 & 0.000 \\
\hline & \multicolumn{4}{|c|}{ Log Likelihood Function $=-787.697$} \\
\hline & \multicolumn{4}{|l|}{$\mathrm{AIC}=4.736$} \\
\hline & \multicolumn{4}{|l|}{$\mathrm{BIC}=4.827$} \\
\hline & \multicolumn{4}{|c|}{ McFadden Pseudo $\mathrm{R}_{\mathrm{p}}^{2}=0.705$} \\
\hline & \multicolumn{4}{|l|}{ Vuong Test $=6.140$} \\
\hline
\end{tabular}

Table 3 - Total number and crashes at urban intersections with semi-actuated signal control

\begin{tabular}{||l|c|c|c|c|c|c||}
\hline \multicolumn{1}{|c|}{ Intersection } & 2007 & 2008 & 2009 & 2010 & 2011 & 2012 \\
\hline \hline Numbers & 8 & 10 & 10 & 10 & 10 & 10 \\
\hline Semi-actuated signal control implemented & 1 & 5 & 9 & 10 & 10 & 10 \\
\hline Fatal crashes & 2 & 1 & 0 & 0 & 2 & 0 \\
\hline Injury A & 8 & 5 & 8 & 7 & 4 & 4 \\
\hline Injury B & 19 & 11 & 20 & 21 & 20 & 16 \\
\hline Total & 29 & 17 & 28 & 28 & 26 & 20 \\
\hline
\end{tabular}


rear end \& side swipe, and head-on crashes [23]. For each of evaluation of crash types, safety impacts in terms of percentages of reductions or increments of injury and total crashes were calibrated for urban intersections with semi-actuated signal control.

As result of EB approaches, Figures 2 and 3 illustrate the safety impacts of semi-actuated signal control for injury and total crashes, respectively, at urban intersections in Daejeon. The semi-actuated signal controls could, on the average, increase injury crashes by around $5.9 \%$ for all crash types. However, in three targeted vehicle crash types (angle, sideswipe \& rearend, and head-on) with semi-actuated signal controls, EB analysis results showed different consequences for all crash types, with a reduction in injury crashes of over $7.7 \%$. This suggests that semi-actuated signal controls have positive safety impacts on urban intersection in Daejeon.

The semi-actuated signal controls will increase total crashes by $3.8 \%$, on the average. However, in specific types of targeted crashes related to urban intersections with semi-actuated signal controls (including angle, sideswipe \& rear-end, and head-on), EB analysis showed different results for all crash types as same as injury crash results, with a reduction of total crashes of around 9.2\%.

In addition, with EB analysis, each targeted crash type showed similar results for injury and total crashes. In injury crashes, angle and sideswipe \& rear-end crashes were reduced by around $10.9 \%$, respectively, because of semi-actuated signal controls. Additionally, semi actuated signal controls could decrease the average amount of total crashes from angle crashes by about 13.0\%. Moreover, total crashes from sideswipe $\&$ rear-end and head-on crashes affected by semi-actuated signal controls could decrease by about $9.8 \%$ and $20.2 \%$, respectively. All three targeted crash types were affected positively and to a great degree more positively than all crash types. This could be because signal timings and phases can be provided reasonably by traffic conditions at each intersection.

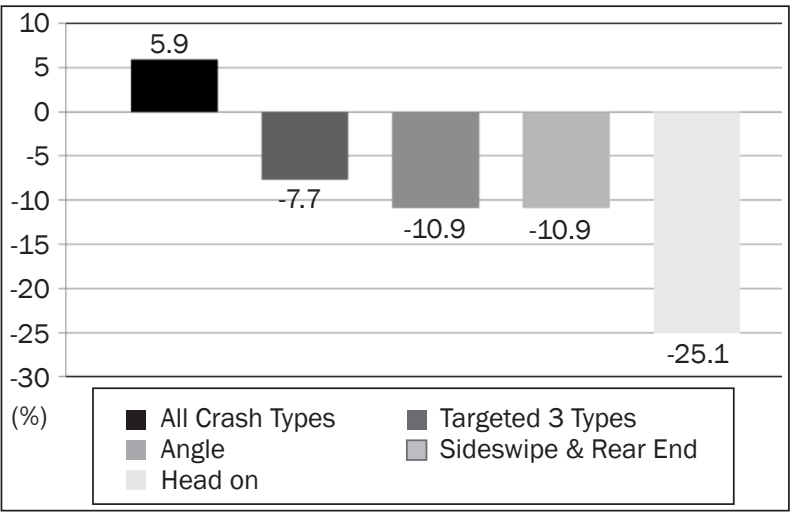

Figure 2 - EB analysis results of injury crashes

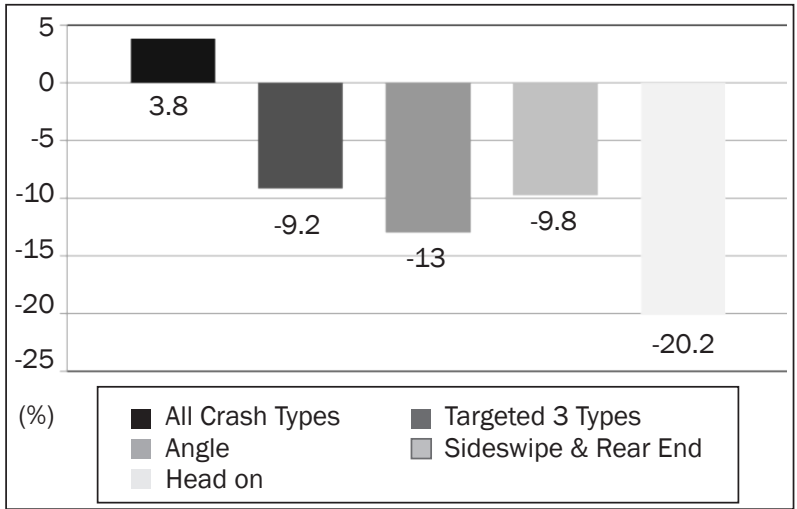

Figure 3 - EB analysis results of total crashes

\section{RESULTS}

This study analyzed the safety impacts for urban intersections equipped with semi-actuated signal controls in Daejeon Metropolitan City, Korea. A large number of previous studies on fully actuated and semi-actuated signal controls have focused on the optimization of signal timing and the minimization or maximization of green times. Only a few studies found that optimal signal timing with certain techniques or algorithms can improve traffic safety at urban and rural intersections. However, it is difficult to provide numerical evidence for determining the safety impacts of actuated signal controls. Therefore, this study has conducted practical analysis of the safety impacts of urban intersections equipped with semi-actuated signal controls using vehicle crash data from the period of 2007-2012 as well as EB approaches.

In order to use EB approaches for the safety impact of semi-actuated signal controls, data collection, data processing, and preliminary data analysis were carried out to obtain the distribution of dependent variables and to identify variables that affect the occurrence of vehicle crashes at urban intersections. Second, safety performance functions were established for injury and total crashes at urban intersections without semi-actuated signal controls, which were used as comparison groups. This study has shown that the zero inflated Poisson regression with normal heteroscedasticity was an appropriate model for both injury and total crashes, considering factors such as geometrics, vehicle crash, and traffic volume data. Finally, EB analysis has been conducted to examine the safety impacts of urban intersections with semi-actuated signal controls.

As the results showed, the semi actuated signal controls increased injury crashes of all crash types by around 5.9\%. Concerning crash types, such as angle, rear-end \& sideswipe, and head-on crashes, semi-actuated signal controls decreased injury crashes by around $7.7 \%$. Similar to injury crashes of the three 
aforementioned crash types, total crashes decreased by around $9.2 \%$ due to the implementation of semi-actuated signal controls. For each crash type associated with urban intersections, injury crashes involving angle, sideswipe \& rear-end, and head-on crashes decreased by $10.9 \%, 10.9 \%$ and $25.1 \%$, respectively, and total crashes involving angle, sideswipe \& rearend, and head-on crashes decreased by $13.0 \%, 9.8 \%$ and $20.2 \%$, respectively. This may be a result of reasonable signal systems considering traffic conditions and prevention of red light violations. According to the preliminary data analysis of historical data from Daejeon Metropolitan City, a large proportion of crashes in urban intersections with semi actuated signal controls occurred at peak times of the day. Additionally, vehicle crashes caused by red light violations tended to occur mainly at an off-peak time of day.

\section{CONCLUSION}

In this respect, vehicle crash data from urban intersections with semi-actuated signal controls and vehicle crashes related to red light violations need to be assessed for the safety impacts associated with semi-actuated signal control implementations. Additionally, considering safety impact factors, such as AADT, number of lanes, speed limits, left turn pockets and front traffic signals would help improve safety associated with semi-actuated signal controls as well as minimise travel times.

To analyze the safety impacts of semi-actuated signal control implementations, SPFs need to be developed using Daejeon metropolitan city data. However, some important data, such as the number of property damage only crashes (PDOs), geometric design details, and other factors affecting safety performances were not obtained for the purpose of this study. Therefore, the improved data collection will certainly enhance the statistical significance of SPFs. Moreover, the safety impact analysis can be conducted with larger amounts of data and longer historical records of vehicle crashes.

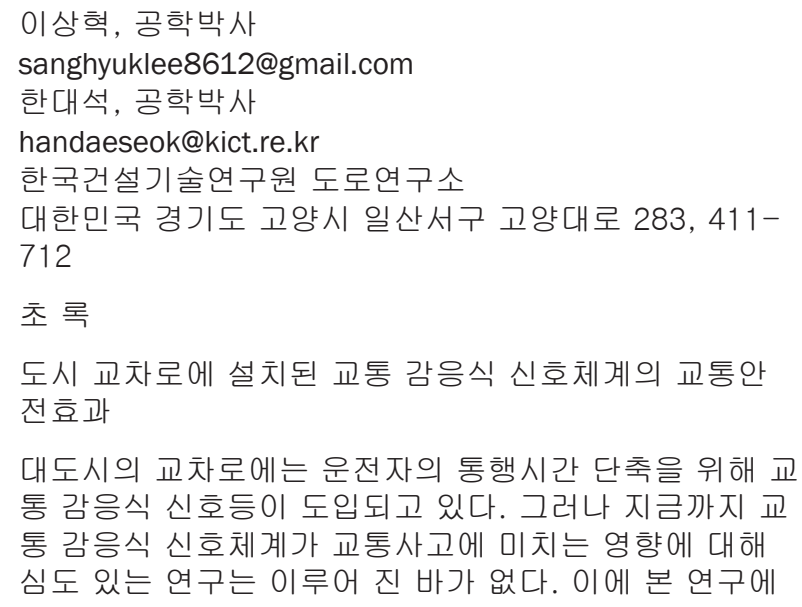

서는 교통사고모형과 경험적 베이지안 모형을 활용하여 도심지 교차로에 설치된 교통 감응식 신호체계가 교통안 전에 미치는 영향을 정량적으로 분석하고자 하였다. 그 결과 교통 감응식 신호체계는 교통안전에 영향을 미치고 있는 것으로 분석되었다. 모든 유형의 교통사고에서는 총 사고건수와 부상사고 건수가 각각 $3.8 \%, 5.8 \%$ 증가 한 것으로 나타났으나, 교차로에서 발생하는 주요 교통 사고 유형(정면충돌, 측면추돌, 후방추돌 등)의 총 사고 건수는 $9.2 \%$ 감소, 부상사고 건수도 $7.7 \%$ 감소하는 것 으로 분석되었다. 이러한 결과는 교통 감응식 신호체계 가 총 지체시간을 고려한 최적의 현시를 제공함으로써, 교통류 혼잡으로 인한 상충의 조건을 완화시켰기 때문이 라고 판단된다.

핵심용어 :

교통 감응식 신호체계, 교통안전, 교통사고모형, 경험적 베이지안 모형, 도시 교차로

\section{REFERENCES}

[1] Oh JT. Development of Severity Models for Vehicle Accident Injuries for Signalized Intersections in Rural Areas. KSCE J of Civil Engineering. 2006;10(3):219-225.

[2] Young W, Archer J. Traffic Microsimulation Modeling to Study a Traffic Signal Incident Reduction Function. Transport Res Record. 2009;2103:80-87.

[3] Li W, Tarko AP. Safety Consideration in Signal Coordination and Road Design on Urban Street. Presented at the 4th International Symposium on Highway Geometric Design; 2010.

[4] Yun IS, Lee CK, Choi JH, Ko SJ. Safety Assessment of Signalized Intersection Using SSAM: A Case of Actuated Signal Control. J Korea Society of Intelligent Transportation System. 2011;10(6):1-14.

[5] Kim Y, Huh JA. Development of an Actuated Traffic Signal Control Strategy to Minimize Dilemma Zone. J Korea Society of Intelligent Transportation System. 2002;1(1):58-69.

[6] Lord D, Persaud BN. Accident Prediction Models With and Without Trend: Application of the Generalized Estimating Equations (GEE) Procedure. Presented at 79th Annual Meeting of the Transportation Research Board; 2000.

[7] Ma J, Kockelman KM. Bayesian Multivariate Poisson Regression for Models of Injury Count, by Severity. Transport Res Record. 2006;1950:24-34.

[8] Persaud BN, Palmisano J. Calibration and Transferability of Accident Prediction Models for Urban Intersections. Transport Res Record. 2002;1784:57-64.

[9] Heydecker BG, Wu J. Identification of Sites for Road Accident Remedial Work by Bayesian Statistical Methods: An Example of Uncertain Inference. Advances in Engineering Software. 2001;32:859-869.

[10] Miaou SP, Lord D. Modeling Traffic Crash-Flow Relationships for Intersections: Dispersion Parameter, Functional Form, and Bayes Versus Empirical Bayes. Presented at 82 nd Annual Meeting of the Transportation Research Board; 2003.

[11] Lord D, Washington SP, Ivan JN. Poisson, Poisson-Gamma and Zero-Inflated Regression Models of Motor Vehicle Crashes: Balancing Statistical fit and Theory. Accident Analysis Prevention. 2005;37:35-46. 
[12] Chin HC, Quddus MA. Applying the Random Effect Negative Binomial Model to Examine Traffic Accident Occurrence at Signalized Intersections. Accident Analysis Prevention. 2003;35(2):253-259.

[13] Hauer E. Overdispersion in Modeling Accidents on Road Sections and in Empirical Bayes Estimation. Accident Analysis Prevention. 2001;33(6):799-808.

[14] Li CS, Lu JC, Park JH, Kim K, Brinkley PA, Peterson JP. Multivariate Zero-Inflated Poisson Models and Their Applications. Technometrics. 1999;41(1):29-38.

[15] Xi X, Saric Z, Kouhpanejade A. Freeway Incident Frequency Analysis Based on CART Method. Promet - Traffic \& Transportation. 2014;26(3):191-199.

[16] Jovanis PP, Chang H. Modeling the Relationship of Accidents to Miles Traveled. Transport Res Record. 2002;1068:42-51.

[17] Li Z, Lee SH, Lee YD, Zhou B, Bamzai RA. Methodology for Assessing the Safety Impacts of Highway Shoulder Paving. Presented at T \& DI Congress; 2010.
[18] Carlin BP, Louis TA. Bayesian Methods for Data Analysis. CRC press, New York; 2009.

[19] Greene WH. NLOGIT Version 3.0 User's Manual. Econometric Software Inc., Bellport, NY; 2002.

[20] Persaud B, Lyon C, Nguyen T. Empirical Bayes Procedure for Ranking Sites for Safety Investigation by Potential for Safety Improvement. Transport Res Record. 1999;1665:7-12.

[21] Jeong SB, Hwang BH, Sung NM, Lee SH. Development of Evaluation Model for Black Spot Improvement Priorities by Using Empirical Bayes Method. J Korean Society of Transportation; 27(3):81-90.

[22] Kwak YH. An Effect Analysis on the Improvement Strategies of Traffic Accident Area using Empirical Bayes Method. Master Degree Thesis, Hanyang University; 2006.

[23] Bukljas Z, Culjak I, Zovak G. Using Traffic Conflict Method in Evaluating Traffic Safety at the Reconstructed Intersection, Promet - Traffic \& Transportation. 2002;14(3):135-139. 